\title{
Design on Highway Information Publishing System and Benefit Analysis of Traffic Control System
}

\author{
Wei Li ${ }^{1, a}$, Guodong Han² \\ ${ }^{1}$ School of Electronic and Control, Chang'an University, Xi'an, Shaanxi, 710064, China \\ ${ }^{2}$ CHINA MCC20 GROUP CORP., LTD. Shanghai 201900, China \\ azurish1975@163.com
}

Key words: highway, traffic control, information publishing system, intelligent transportation.

\begin{abstract}
With the purpose of offering dynamic information services for road users, the information publishing scheme is proposed based on variable message sign and variable speed limit sign. And the information publishing system shared information control center with public transportation service system is established. The economic benefit of intelligent traffic control system is quantitatively studied by radar map method for the first time. Research shows that intelligent traffic control system has reached ideal-steady state. The research results reduce traffic congestion and improve the highway utilization and traffic management efficiency.
\end{abstract}

\section{Introduction}

With the rapid development of highway, the number of motor vehicles surges and it results in the phenomenon of traffic congestion serious year by year in most parts of China, thus economic losses increases. Therefore, the demands on improving road capacity, enhancing traffic management and promoting traffic management information are greater. The application of information technology in transportation field expresses intelligent transportation system. The extensive researches on intelligent traffic management have conducted at home and abroad [1-6], and mostly for urban roads, few studies on arterial highway. While the research on benefit of traffic control system is also less [7-8]. Therefore, highway information publishing system is studied mainly for public service and the traffic efficiency of intelligent traffic control system is evaluated using radar chart method in this paper.

\section{Composition and Work Flow of Highway Information Publishing System}

Highway information publishing system is an important part of traffic guidance system. It provides real-time dynamic traffic information service for drivers. The information publishing system composition is shown in Fig. 1.

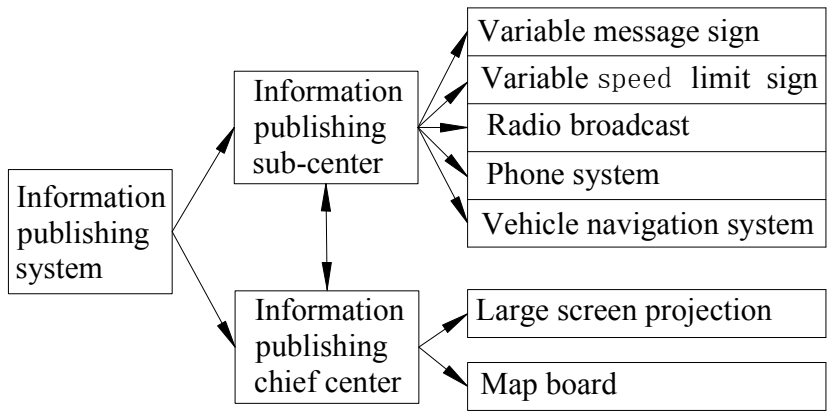

Fig. 1 Highway information publishing system composition 
(1)Information publishing center. Information publishing center is composed of information publishing chief center and some information publishing sub-centers. Information publishing chief center includes map board and large screen projector used to monitor for manager. Information publishing sub-center is a part of monitoring sub-center and formed mainly by local area network. (2) Variable message sign. The signs are installed in the place that before the road intersection $100 \sim 200 \mathrm{~m}$. In order to early understand the congestion condition in front of the road for drivers and prepare to do bypass, the extent of road congestion can be divided four grades to display: red for severe congestion, orange for moderate congestion, yellow for slight congestion, green represents normal state. Refresh frequency is $8 \mathrm{~s}$, guidance information generation rate is $60 \sim 120 \mathrm{~s}$. Guidance information is provided by Chinese characters and graphics, the Chinese character is represented by $32 \times 32$ lattice. (3) Speed limit (information) sign. Variable speed limit sign can only display the speed limit value, while variable speed limit message sign can also display speed limit reason showed by a number of Chinese characters. After the driver knows the speed limit reason, he will pay more attention to the speed limit to be strictly enforced. (4)Roadside radio. Radio transmitter device is set up in the roadside, it sends traffic information by frequency modulation (FM) or amplitude modulation (AM), and the drivers can listen to through car radio. Different information is played in different road section by different frequencies.

The function of information publishing system mainly includes travel guidance, severe weather warning, road construction and traffic congestion warning, other warning, such as the visual distance warning, lane restriction, speed limit and so on.

The work flow of information publishing system: the traffic data information is processed in highway public transportation service center, and then is sent to the information publishing system control center. The operator appropriately controls information and data on the basis of obtained traffic information, and then inputs traffic information on the central control compute of information publishing system in order to post to the specified variable message sign. After variable message sign controller receives the information, firstly judges whether the information is complete and correct, if incomplete, the report to the central control computer that instruction is incorrect, not to execute; otherwise answers that the instruction has been received correctly, and then extinguishes all the light bulbs, drives raster to form display character, and then lights up the bulbs to display information. Once again, reporting to the central control computer that the instruction is properly executed. The flow chart is shown in Fig. 2.

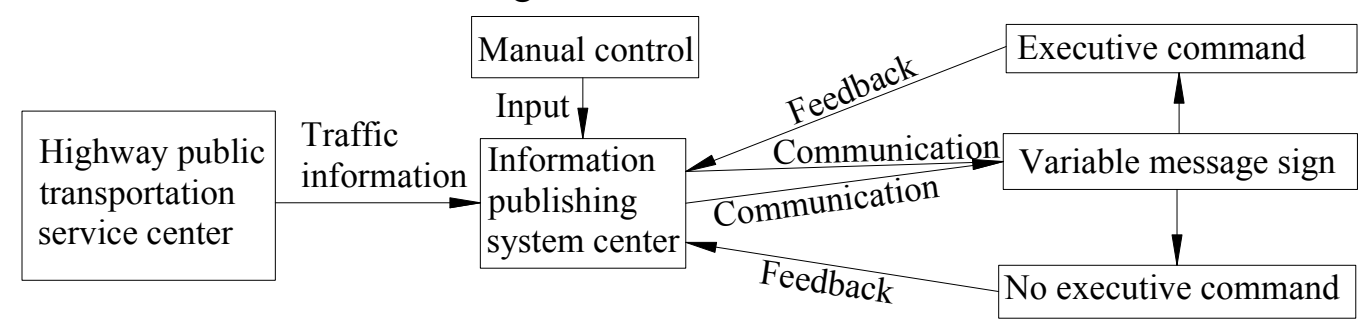

Fig. 2 Information publishing system flow chart

\section{Design on Highway Information Publishing System}

The publishment of road information is achieved mainly through variable message sign and variable speed limit sign. Variable message sign is used to provide traffic information and guidance-control instruction for drivers. Variable speed limit sign is used to provide speed limit order, and briefly explain the reasons for speed limit. The following table is information publishing scheme proposed based on different road condition. 
Table 1 Information publishing scheme under different road condition

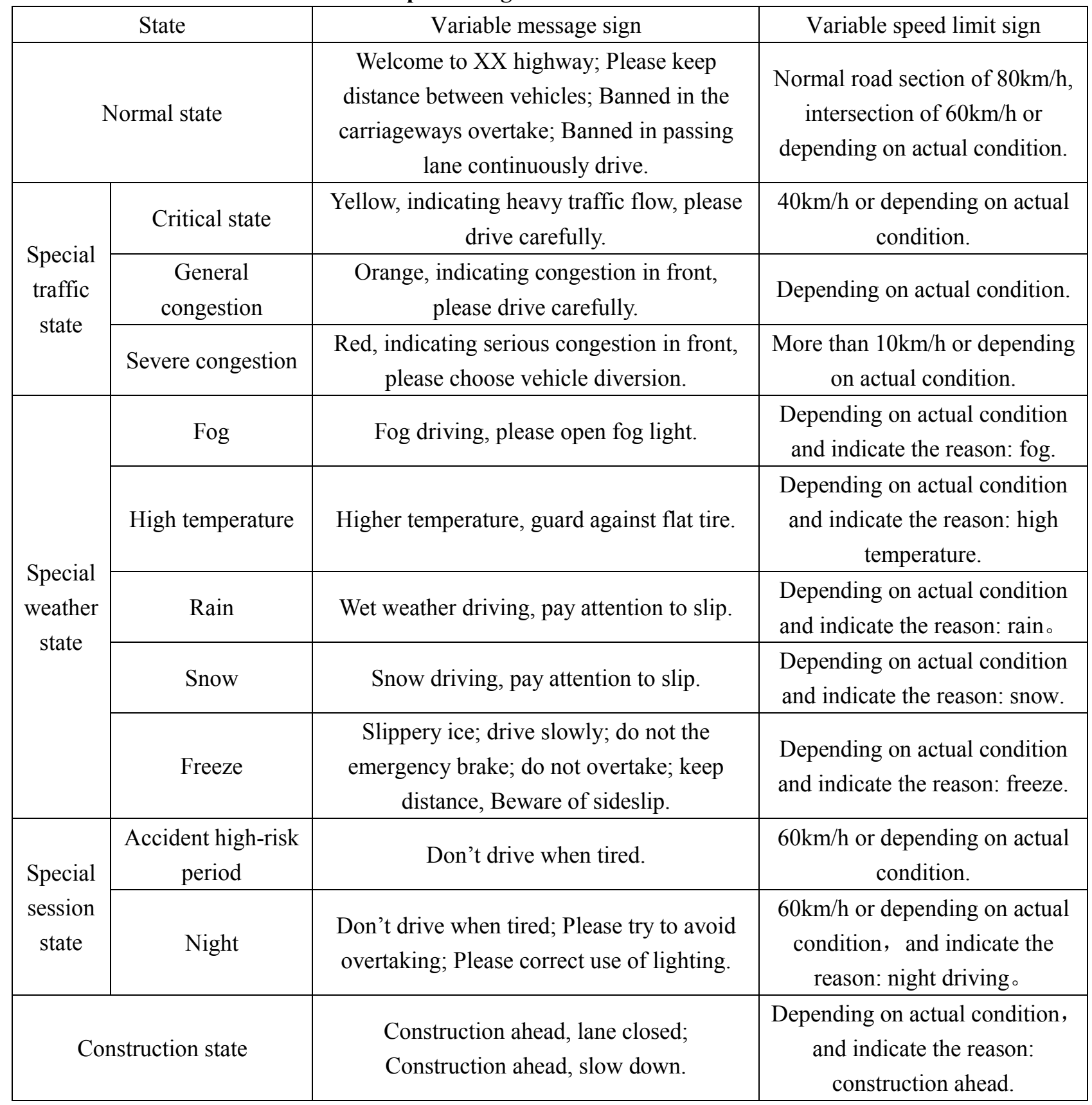

\section{Benefit Analysis of Traffic Control System}

Evaluation methodology and indexes system of benefit analysis. Radar map is a solid form for financial analysis. It is mainly used to evaluate enterprise operation state- profitability, productivity, mobility, security and growth. In this paper, the benefit is comparatively analyzed before and after application of the intelligent traffic control system, and the efficiency of each period is studied to analyze the reason.

The smallest circle of three concentric circles formed radar chart represents one half of industry average level or the worst case. Center circle represents industry average level or the level of specific comparison object, it is called the standard line (area). Great circle represents 1.5 times of industry average level or the best condition. The five sub-areas (each area is 72 degrees) separately represent profitability, productivity, mobility, security and growth of the enterprise. The ratio line represents various operating ratios in settlement period. After linking up various ratio values, the 
irregular closed loop map is formed. Enterprise operation state is clearly showed, compared with the standard line, and you can clearly see the achievements and gaps of enterprise. Radar analysis method is that if the ratio of enterprises is less than the standard line, it shows the ratio value of enterprise is lower than industry average level, should analyze the causes and proposed improvement direction; if the ratio value of enterprise is close to or below the small circle, it shows the enterprise is in a very dangerous situation, an urgent need of reform measures to reverse the situation; if the ratio value of enterprise is more than center circle or the standard line or even close to great circle, it shows the advantages of business is obvious, should be consolidated and developed.

According to application characteristics of intelligent traffic control system and index selection of radar map, reasonable evaluation indexes system is set up to objectively reflect application results of the system. Indexes system of traffic control system is shown in Table 2.

Table 2 Indexes system for benefit evaluation

\begin{tabular}{|c|c|c|c|c|c|}
\hline $\begin{array}{c}\text { First } \\
\text { index }\end{array}$ & Security & Patency & Profitability & Growth & $\begin{array}{c}\text { Environmental } \\
\text { protection }\end{array}$ \\
\hline $\begin{array}{c}\text { Secondary } \\
\text { index }\end{array}$ & $\begin{array}{c}\text { Safe passage } \\
\text { rate, early } \\
\text { warning } \\
\text { effective }\end{array}$ & $\begin{array}{c}\text { The frequency of wait } \\
\text { time less than 20s, the } \\
\text { frequency of waiting } \\
\text { for less than 2 lights }\end{array}$ & $\begin{array}{c}\text { Capital gains } \\
\text { rate, capital } \\
\text { utilization }\end{array}$ & $\begin{array}{c}\text { Growth rate of } \\
\text { traffic volume, } \\
\text { growth rate of } \\
\text { vehicle speed }\end{array}$ & $\begin{array}{c}\text { Compliance rate of } \\
\text { acoustic environment, } \\
\text { passing rate of air } \\
\text { quality }\end{array}$ \\
\hline
\end{tabular}

Benefit analysis of traffic control system. According to the survey of various indexes before and after application of intelligent traffic control system, radar map is drawn based on the relative percentage of survey data and industry average level, the effectiveness of traffic control system is analyzed. The unit is \%, the result shown in Fig. 3.

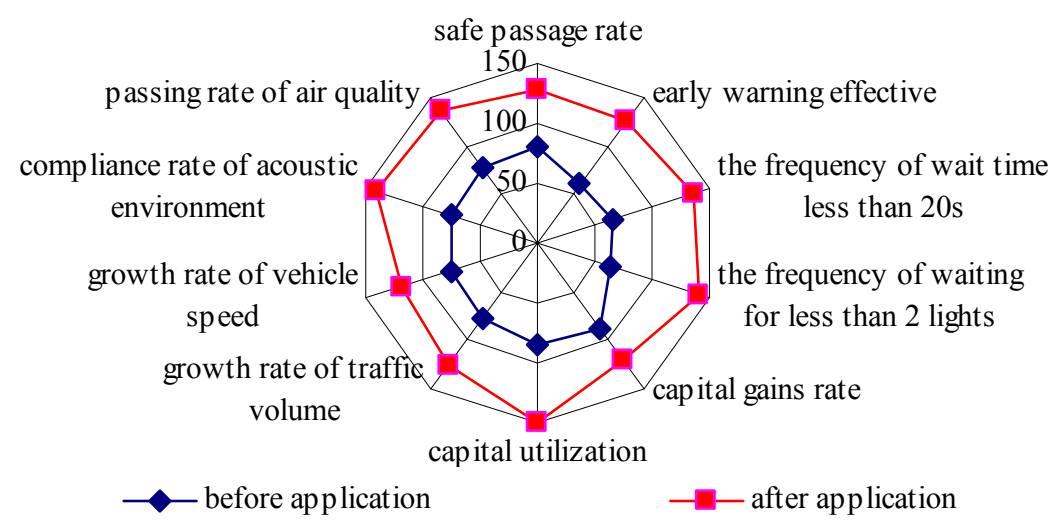

Fig. 3 The radar chart for benefit analysis of traffic control system

Can be seen before the application of intelligent traffic control system, the five indexes are located within the industry average level such as security, patency, profitability, growth and environmental protection. Especially the security and patency are only slightly higher than one half of industry average level, showing be more inadequate. After the application of intelligent traffic control system, the five indexes are more evenly distributed in the standard area, and at a high level, especially patency, profitability and environmental protection are close to 1.5 times of industry average level. It shows in ideal-steady state, the indexes are balanced and coordinated, and it is very conducive to the highway development. Intelligent traffic control system is a very effective means of traffic management and control. Although the need to increase construction investment, based on 
market research on such products, compared investment costs with annual savings of manpower, material, accident damages compensation, etc., it is a project that both short-term benefit and long-term benefit are good.

\section{Conclusion}

(1) The information publishing system shared information control center with public transportation service system is established. The different information publishing scheme is proposed under normal state, special traffic state, special weather state, special session state and construction state.

(2) The economic benefit of intelligent traffic control system is studied by radar map method including security, patency, profitability, growth and environmental protection indexes. After application of intelligent traffic control system, the indexes are balanced and coordinated, and it shows in ideal-steady state.

\section{References}

[1] Yang Xiaoguang, Huang Wei, Ma Wan-jing. Method of Delimiting Urban Traffic Signal Coordinate Control Subarea under Oversaturated Condition, Journal of TongJi University (Natural Science), Vol.38 No.10 (2010), p.1450-1457.

[2] Yu Dexin,Yang Zhaosheng,WangYuan, Sun Jian-ping. Urban Road Traffic Control System and Its Coordinate Optimization Based onMulti-Agent System, Journal of Jilin University (Engineering and Technology Edition), Vol.36 No.1 (2006), p. 113-118.

[3] Zhang Bing, Deng Wei, Jiang Guiyan. Design of Database for Traffic Information Promulgation System Based on GIS, Journal of Wuhan University of Technology (Transportation Science \& Engineering), Vol.34 No.1 (2010), p. 15-18.

[4] Wang Yuan, Yang Zhaosheng, Guan Qing, Yang Chao. Regional traffic control strategy optimization method based on H-SVMs, Journal of Jilin University (Engineering and Technology Edition), Vol.39 No.1 (2009), p. 38-44.

[5] Yu Yuxin. Study on Transport Evaluation and Control Management Technology for Arterial Highway, Xi'an: Chang'an University, 2010.

[6] Huang Meiling, Tang Wei, Gao Wei, etc. Design and Development of Urban Traffic Information Release System, Journal of ChongQing JiaoTong University (Natural Science), Vol.29 No.4 (2010), p. 616-619.

[7] He Jianwei, Zeng Zhenxiang, Li Zhiheng. Benefit Evaluation Framework of Intelligent Transportation Systems, Journal of Transportation Systems Engineering and Information Technology, Vol.10 No.1 (2010), p. 81-87.

[8] Yang Xiaoguang,Yun Meiping. Evaluation Measures of Traffic Benefits for Urban Traffic Control Systems and Related Correlative Analysis, Journal of Highway and Transportation Research and Development, Vol.21 No.10 (2004), p. 81-84. 